\title{
Forecasting the Gold Returns with Artifical Neural Network and Time Series
}

\author{
Habip Kocak ${ }^{1} \&$ Turgut $\mathrm{Un}^{1}$ \\ ${ }^{1}$ Faculty of Economics, Department of Econometrics Goztepe, Marmara University, Istanbul, Turkey \\ Correspondence: Habip Kocak, Faculty of Economics, Department of Econometrics Goztepe, Marmara \\ University, Istanbul, Turkey. E-mail: hkocak@marmara.edu.tr
}

Received: September 3, 2014

Accepted: September 22, $2014 \quad$ Online Published: October 25, 2014

doi:10.5539/ibr.v7n11p139

URL: http://dx.doi.org/10.5539/ibr.v7n11p139

\begin{abstract}
Gold is an important investment tool especially in developing countries. Return-on-gold and prediction thereof is a topic which has been attracting the attention of investors and densely studied recently. For this reason different methods are being used to predict return-on-gold and effectiveness of these methods are being compared.

The purpose of this study is to generate a prediction of return-on-gold using artificial neural networks and GARCH and its derivatives, which is a conventional time series method, based on the series obtained from the return of gold values provided by Turkish Gold Exchange belonging to the February 2014 and June 2014 period.
\end{abstract}

As a result of this study, contrary to the expectations and the majority of similar studies, ANN provided less successful outcomes compared to GJR GARCH method.

Keywords: gold, gold prediction methods, GARCH, Artificial Neural Networks

\section{Introduction}

Predicting the future on the basis of past time data is one indispensable tool of financial markets in particular. When these markets are examined, no single method stands out as able to precisely model the direction of movements due to the multiplicity of variables and the volatility of the elements that form these markets. For this reason, financial markets accommodate more risks compared to other fields of investment.

Time series is more than just providing an economic and statistical model; they consist of a combination of the past values of the data to be predicted with the present and past values of the previous random unexpected changes. When time series approach is evaluated in terms of cost and benefit, it can be seen that (i) they are mostly used in short-term predictions, developing an econometric model of the variable to be predicted is a highly time- and energy-consuming task, and (iii) huge amount of data is needed so that an effective time series model can be developed (Griffiths et al., 1993, p. 640).

Modelling of the changing variance in financial time series can be performed with GARCH models. The volatility which can be seen especially in high-frequency time series causes the covariance hypothesis to lose its validity. It is not possible to explain such models with linear models (Floros, 2008, pp. 31-41). Variances of financial time series usually show variance in a time-dependent manner.

Developed by Engle (1982), ARCH model stands out as the first model which takes into consideration the characteristics in the returns of financial assets. Engle found out that when unconditional variance is fixed and conditional variance is time-dependent, the taller is a function of the squares of error terms. ARCH model was improved in time and paved the way for the development of a so-called ARCH family which accommodate different viewpoints and impacts.

Bollerslev (1986) added ARMA process to the conditional variance structure of ARCH models, as a result of which GARCH models can include more past data and a more flexible delay structure.

Nelson (1991) developed the exponential GARCH (EGARCH) model in order to explain the asymmetric volatility structure existing in financial markets which can be observed in series. Asymmetric structure is completed with leverage effect in EGARCH model.

Glosten, Jagannathan and Runkle (1993) displayed another model structure receiving asymmetric effect. In their conditional variance model called GJR-GARCH model, conditional variance value shows different reactions to 
negative or positive changes.

Artificial neural networks (ANN) are one of the artificial intelligence topics and methods which has been used for prediction recently. ANN is preferred for predictions due to its multiple variance and non-parametric structure and predisposition for application in non-linear time series. ANNs are especially suitable for solving the problems which cannot easily be mathematically modelled; they also have the ability to learn new conditions by changing their weights and they can learn with different learning algorithms, which allows for the learning to be used in solving similar problems as a result of such learning. A trained ANN can act as a specialist, analyse the data that is given and make projections.

The price of gold is one of the important market instruments; both investors and decision makers desire to determine its future value. Investing in gold usually aims protection from inflation, political risks and crisis in the long term and utilization from price fluctuations in the short term. Its long history and wide acceptance by economic units has made the gold and its volatility, which is an indicator of risk in gold, an essential topic. Most of the studies provide a safe investment tool for investors in unsteady periods. Different methods are being used for predicting the prices of gold which are subject to comparison in order to determine the best performing one.

The purpose of this study is to examine the impact of ANN on determination of gold prices returns by using a time-series analysis method, GARCH models.

\section{Literature Review}

Those people who have to make investment decisions, especially economist and decision-makers, make predictions about the future. For this effect much effort is paid on the prediction of economic data such as stock market, exchange rate, inflation and gold.

Prediction methods in time series, which are especially favoured by econometrists, have performed more effective predictions by integrating themselves into new techniques by means of developed computer technology.

Artificial neural networks have been a widely studied method of prediction in the literature recently. Several economists have used ANN as a prediction method in time series and obtained successful results (Özkan, 2013; Choudhary \& Haider, 2013; Elçin et al., 2011; Kryzanowski et al., 1993; Moshiri and Cameron, 2009; Fahimifard et al., 2009; Donaldson \& Kamstr, 1997; Melike \& Özgür, 2012). Some others compared ANN with conventional time series prediction method and found successful (Sharda \& Patil, 1992; Chakradi \& Simhon, 2007; Baker \& Richards, 1999; Ntungo, 1996; Hanofizadeh et al., 2008; Saiful \& Yoshiki; 2011), whereas some economists found conventional methods more successful (Nitin et al., 2011). Several studies used hybrid methods which is a combination of econometric methods and ANN (Mammadagha et al., 2007; Hamzaçebi, 2008; Termizel et al. 2005; Nitin et al., 2010; Diaz et al., 2008; Zhang, 2003; Hui et al., 2012).

There are several studies performed on gold prices especially recently. In some studies, ANN stands out in some of them due to its supremacy; in some others it appears in comparison with conventional methods (Özdemir et al., 2013; Chamzini and Yakchali, 2013; Parisi et al., 2008; Shafiee and Topal, 2010; Lineesh et al., 2010; Roy and Singh, 2014).

Tully and Lucey (2007) examined the movements in gold prices with ARCH-GARCH analysis and found out that the returns on stock certificates decreased when the price of gold increased.

Shafiee and Topal (2010) examined 40 years of gold and found a high correlation between gold and oil prices. Capie et al. (2005) investigated the relation between weekly gold prices and pound-USD and yen-UD parities for 33 years and the behaviour of gold as an instrument for avoiding exchange rate risks based on GARCH, threshold GARCH and exponential GARCH methods. They concluded that GARCH model was the most suitable one which statistically showed that gold provided protection from exchange rate risks.

Do et al. (2009) examined the relation between volatility of stock markets in some ASEAN countries, namely Indonesia, Malaysia, Thailand and Vietnam, and the returns of international gold market with GARCH and GJR models. They found out that, with the exception of Vietnam, GJR $(1,1)$ was the most suitable model.

\section{Artifical Neural Networks}

Artificial neural networks (ANNs) are the general term used for computer systems which have working principles similar to the neural systems of human body. It involves studies directed at training and teaching of computers. They are also computer programs that simulate the neural networks of human brain. ANNs allow for reaching better solutions compared to linear methods due to its non-linear structure and probabilistic behaviours.

ANNs are data-based systems formed by lamellar connection of artificial neural cells; they simulate some abilities of human brain such as learning and fast decision-making under various conditions through simplified 
models in order to solve complex problems.

The most generic ANN model is seen below.

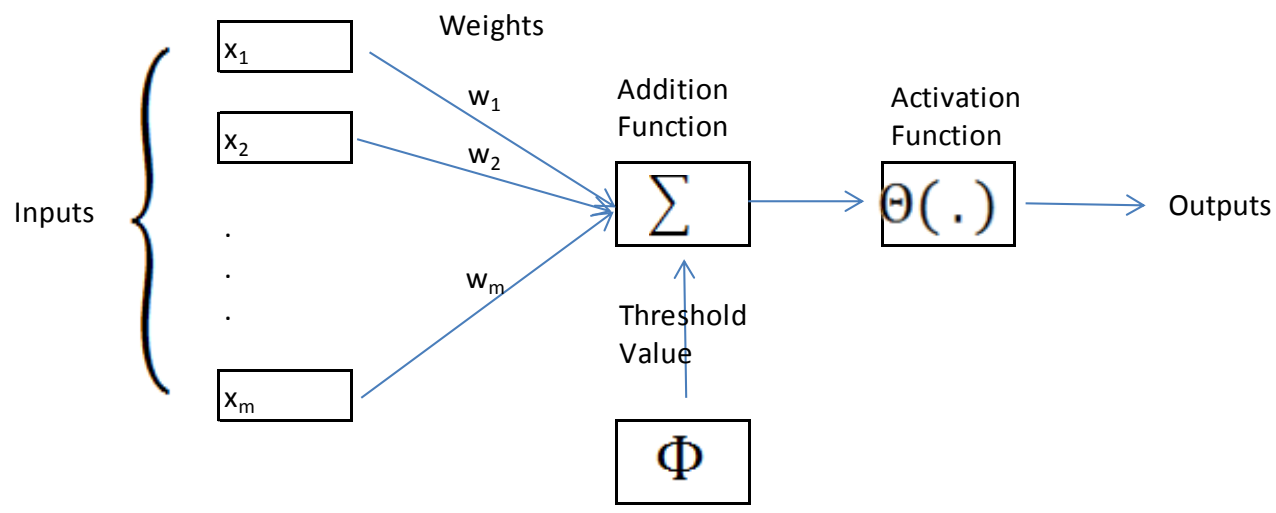

Figure 1. The most generic Artificial Neural Network model

Inputs $\left(x_{1}, x_{2}, \ldots, x_{m}\right)$ are the information that entre the cell from other cells or the environment. These are determined by the examples that the network is asked to learn. Weights $\left(w_{1}, w_{2}, \ldots, w_{m}\right)$ are the values that express the impact of a process of elements on this process of elementsin the input set or another previous layer. Each input is multiplied with the weight values that connect the input to the operation element and combined through the sum function, so that the net information that entering the network is found. The net input of the network is calculated as follows:

$$
\begin{gathered}
\varphi_{i}=\sum_{i=1}^{m} W_{i j} X_{j} \\
X_{i} \in \mathbb{R}^{n} \\
\Theta_{i}=\varphi_{i}+\phi_{i}
\end{gathered}
$$

Where $\Theta_{i}$ shows the total input entering each neuron. $\phi_{i}$ is the threshold value which is a negative or positive value imported from the environment. Another factor that determines the behaviour of neural cell is the activation (transfer) function, which processes the information entering the artificial neural cell and determines the output that will be produced in return for this input. The most widely used transfer functions are threshold, sigmoid, hyperbolic tangent etc. functions (Kaastra, 1996, p. 227). The messages that are sent to the exterior, to itself or to other cells are called "outputs". A neural cell can have multiple inputs whereas it can have only one output, which can act as the input to several cells. Output values can be expressed in functions as follows (Tosunoğlu \& Benli, 2012, p. 543);

$$
\begin{gathered}
\xi_{i}=\psi_{i}\left(\varphi_{i}\right) \\
\xi_{i}=\psi_{i}\left(\varphi_{i}\right)=\psi_{i}\left(\sum_{i=1}^{n} W_{i j}+X_{i}+\phi_{i}\right) \\
X_{i}=\left(X_{1}, X_{2}, \ldots, X_{n}\right) \in \mathbb{R}^{n}
\end{gathered}
$$

Where; $\xi_{i}$ expresses the output of the system or a single neuron, $\phi_{i}$ is the activation function, $\phi_{i}$ is net inputs and $\phi_{i}$ is the threshold value.

ANNs are densely used for time series analysis in recent years. The exercise of obtaining prediction in time series by using artificial neural networks can be summarised in the 7 steps listed below (Benli \& Yildiz, 2012, p. 160):

Step 1: Preliminary processing of data: first, the data are converted into $[0,1]$ interval. If logistic activation function is to be used where $\mathrm{xi}$ is the input (observation) values, the input values are converted into [0, 1] interval as follows:

$$
X_{i}^{*}=\frac{x_{i}-\min \left(x_{i}\right)}{\max \left(x_{i}\right)-\min \left(x_{i}\right)}
$$

Step 2: Decision is made as to percentage share of the dedication and testing sets in data set. Usually $10 \%$ to $20 \%$ 
is used as testing set.

Step 3: In this step, the number of inputs to be used, number of hidden layers, number of units at hidden layer, number of units at output layer, the activation function to be used in these units, learning algorithm and parameters and performance criteria thereof are determined and the ANN model which will be used is constructed.

Step 4: Construction of input values: the input values of ANN are delayed time series. While input values are formed for $X_{t}$, time series, $\mathrm{m}$ (the number of units at input layer) number of delayed time series are constructed as $X_{t-1}, X_{t-2}, \ldots, X_{t-m}$.

Step 5: Calculation of best weight values: the best weight values are found through education set with the selected learning algorithm. Using these obtained best weight values, the output values of the constructed ANN model are calculated.

Step 6: Calculation of performance criteria: testing set estimations of ANN are obtained. The inverse of the conversion applied in step is implemented to the output values obtained in step 5 and the values obtained in this step. The values obtained as a result of this conversion constitute the predictions of education set and testing set, respectively. The selected performance criterion is calculated based on the difference between the prediction of testing set and the data therein. Two of the most widely used performance criteria in the literature are Mean Square Error (MSE) and Mean Absolute Error (MAE) values whose formulas are given below (Zhang, 1998, p. $51)$ :

$$
\begin{gathered}
M S E=\frac{1}{T} \sum_{t=1}^{T}\left(R_{t}-R_{t}^{\prime}\right)^{2} \\
M A E=\frac{1}{T} \sum_{t=1}^{T}\left|R_{t}-R_{t}^{\prime}\right|^{2}
\end{gathered}
$$

Where, T shows the number of predictions, $R_{t}$, shows the real value in t time, and $R_{t}^{\prime}$ shows the mean value of prediction values. The importance of this criterion is that it can dissociate into the variance sums of prediction errors. This feature shows that MSE criterion depends on the second moment of joint distribution of realisation and predictions only. Nevertheless, it must be noted that it cannot provide full information on the actual distribution (Zhang, 1998, p. 51).

Step 7: Prediction: Finally, the best weight values found in step 5 are used to obtain the prediction values for times after testing set, meaning the future, using either iterative prediction method or direct prediction method.

ANNs accommodate several network structures and models. Artificial neural network consists of the interrelation of a series of neural cells in forward-driven and back-propagation connection patterns. Today a number of artificial neural networks have been developed for several purposes and for usage in various fields (Perceptron, Adaline, MLP, LVQ, Hopfield, Recurrent, SOM, ART etc.) Among these, multiple layer forward-driven (Multiple Layer Perceptron-MLP) artificial neural networks are the most widely used; they are also the networks that this study employs.

Back propagation algorithm is an education algorithm which is most widely used for Multiple Layer Perceptron networks.

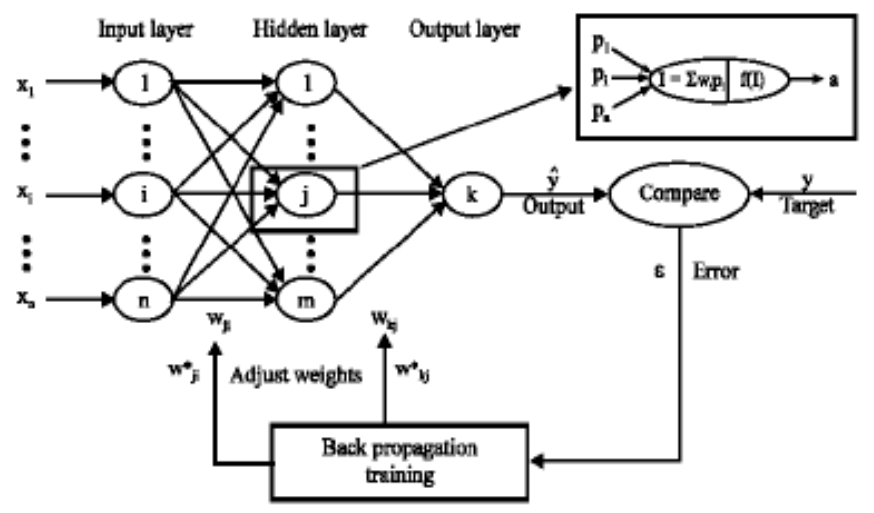

Figure 2. The algorithm of multiple layer back propagation Artificial Neural Networks 
BP (Back Propagation) algorithm is basically realised in two stages. They are (i) the forward stage, where activations are propagated from input to the output layer, and (ii) back stage which back propagates in order to change the error weights and bias values between the real value observed at output layer and desired nominal value. Before the education and test sets inputs and outputs, the feeding work network has to begin education. The model used for time series in ANN is as follows (Ozkan, 2011, p. 187):

$$
y_{t}=G\left(w_{t} ; \psi\right)=\beta_{0}+\sum_{j=1}^{q} \beta_{j} \psi\left(\gamma^{\prime} w_{t}\right)+u_{t}
$$

Where; $y_{t}$ is prediction equation, $\beta=\left(\beta_{1}, \ldots, \beta_{q}\right)^{\prime}, \gamma_{j}=\left(\gamma_{j 0}, \gamma_{j 1}, \ldots, \gamma_{j, k-1}, c_{j}\right)^{\prime}$ and $j=1,2, \ldots, q$ show input neuron number; $w_{t}=\left(w_{1 t}, w_{2 t}, \ldots, w_{k t}, 1\right)^{\prime}=\left(y_{t-1}, y_{t-2}, \ldots, y_{t-k}, 1\right)^{\prime} u_{t}$ show error term and $\psi\left(\gamma^{\prime} w_{t}\right)$ sigma activation function is

$$
\psi\left(\gamma^{\prime} w_{t}\right)=\frac{1}{1+e^{-y_{i} w_{t}}}
$$

GARCH models proposed by Engle (1982) and Bollerslev (1986) are successful in detecting the flat-tailed structure of the distribution and volatility which changes in time. The following section gives the definitions of the models used in the application.

\section{1). ARCH Model}

Variance problem occurs in regression analysis which especially use financial data ARCH model determined this conditional variance as a function of the squares of error terms in t time (Engle, 1982, p. 1002). In ARCH model, it is assumed that the characteristic behaviours of prediction errors depends on regression residuals which will be autocorrelated (Gökce, 1998, p. 57).

$$
\begin{gathered}
\sigma_{t}^{2}=\alpha_{0}+\alpha_{1} \varepsilon_{t-1}^{2}+\cdots+\alpha_{q} \varepsilon_{t-q}^{2}=\alpha_{0}+\sum_{i=1}^{q} \alpha_{i} \varepsilon_{t-i}^{2} \\
\alpha_{0}>0, \alpha_{i} \geq 0 \\
\alpha_{1}+\cdots+\alpha_{q}<1
\end{gathered}
$$

\section{2). GARCH Model}

In GARCH model, the size of conditional variances is a linear function of error squares and conditional variance terms (Bollerslev, 1986, p. 44). In GARCH (p, q) models the variance of error terms is affected both by its own past values and conditional variance values. Less parameters are needed compared to ARCH models.

$$
\sigma_{t}^{2}=\alpha_{0}+\sum_{i=1}^{q} \alpha_{i} \varepsilon_{t-i}^{2}+\sum_{j=1}^{p} \beta_{j} \sigma_{t-j}^{2}
$$

The model has to meet the following conditions so that a successful variance prediction can be made (Bollersley, 1987, p. 542):

$$
\begin{gathered}
\alpha_{0}>0 \quad \beta_{j} \geq 0 \\
\sum_{i=1}^{q} \alpha_{i}+\sum_{j=1}^{p} \beta_{j}<1
\end{gathered}
$$

This condition tells that the sum of parameter values belonging to the conditional variance equation is smaller than it is important for obtaining the finite variance of the model (Green, 1993, p. 570).

Financial series usually show such features as excessive oblateness, volatility clustering and leverage effect, their prediction for the volatility of gold prices with changing variance models can be incomplete and asymmetric conditional variance models can be needed which take into consideration the different impact of negative and positive shocks on volatility. For this reason this model was also included in the following section of the study.

3). EGARCH Model

EGARCH models are also known as exponential GARCH models. Unlike GARCH models which only take into account the size of the input signs, they include the difference of the effects created by negative and positive 
shocks and were proposed by Nelson (1991). The model allows for good or bad news to create different impacts on volatility.

$$
\log \left(\sigma_{t}^{2}\right)=\alpha_{0}+\sum_{j=1}^{q} \beta_{j} \log \sigma_{t-j}^{2}+\sum_{j=1}^{p} \alpha_{i}\left(\left|\frac{\varepsilon_{t-i}}{\sigma_{t-i}}\right|-E\left(\left|\frac{\varepsilon_{t-i}}{\sigma_{t-i}}\right|\right)\right)+\sum_{i=1}^{p} \gamma_{i} \frac{\varepsilon_{t-i}}{\sigma_{t-i}}
$$

The positivity in conditional variance was found without the existence of the condition that parameters should not be negative (Teravista\&Timo, 2009, pp. 34-35)

\section{4). GJR GARCH Model}

The model with threshold value which considers the different and asymmetric effects of positive and negative shocks was proposed by Glosten, Jagannathan and Runkle (1993). An unexpected increase in the series is evaluated as good news which affects the conditional variance with ai parameter. An unexpected fall, on the other hand, is defined as bad news and the conditional variance is affected by $\alpha \mathrm{i}+\gamma \mathrm{k}$ parameter (Chen, 2005 , p.4).

$$
\begin{gathered}
\sigma_{t}^{2}=\alpha_{0}+\sum_{j=1}^{p} \beta_{j} \sigma_{t-j}^{2}+\sum_{i=1}^{q} \alpha_{i} \varepsilon_{t-i}^{2}+\sum_{k=1}^{r} \gamma_{k} \varepsilon_{t-k}^{2} I_{t-k}\left(\varepsilon_{t-k}<0\right) \\
I_{t}=\left\{\begin{array}{cc}
1, & \text { if } \varepsilon_{t}<0 \\
0, & \text { otherwise }
\end{array}\right.
\end{gathered}
$$

On the other hand, leverage effect in GJR GARCH model is quadratic whereas it is exponential in EGARCH (Ozden, 2008, p. 325).

\section{Model and Methodology}

\subsection{Data}

The fundamental purpose o this study is to decide on the precision method which can be used in predicting gold markets. The methods which will be evaluated for this effect are artificial neural networks and time series prediction methods. In our study, the daily-frequency, closing prices (USDs / Ounce) between 12.02.2010, when Turkish Gold Stock Market became a member of the Federation of Euro-Asian Stock Exchanges (FEAS), and 30.06.2014.

In order to display the return of gold, the model used the following return series:

$$
R=\log \left(\frac{G O L D_{t}}{G O L D_{t-1}}\right) * 100
$$

Gold closing prices data and gold return data are given in figures 3 and 4 .

ALT

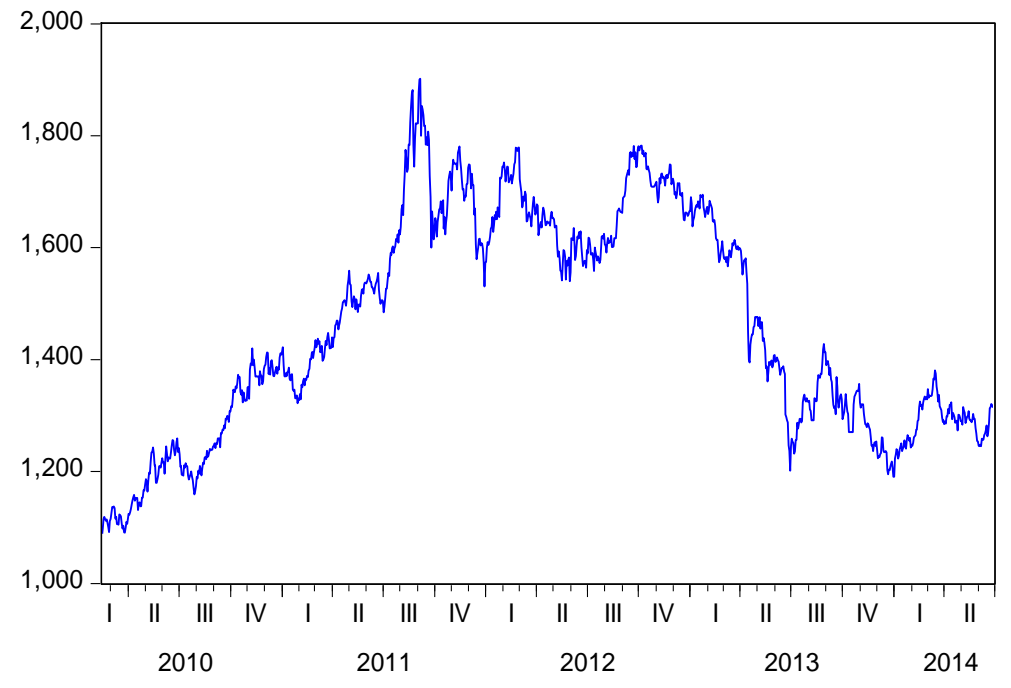

Figure 3. Gold closing prices data 
$\mathrm{R}$

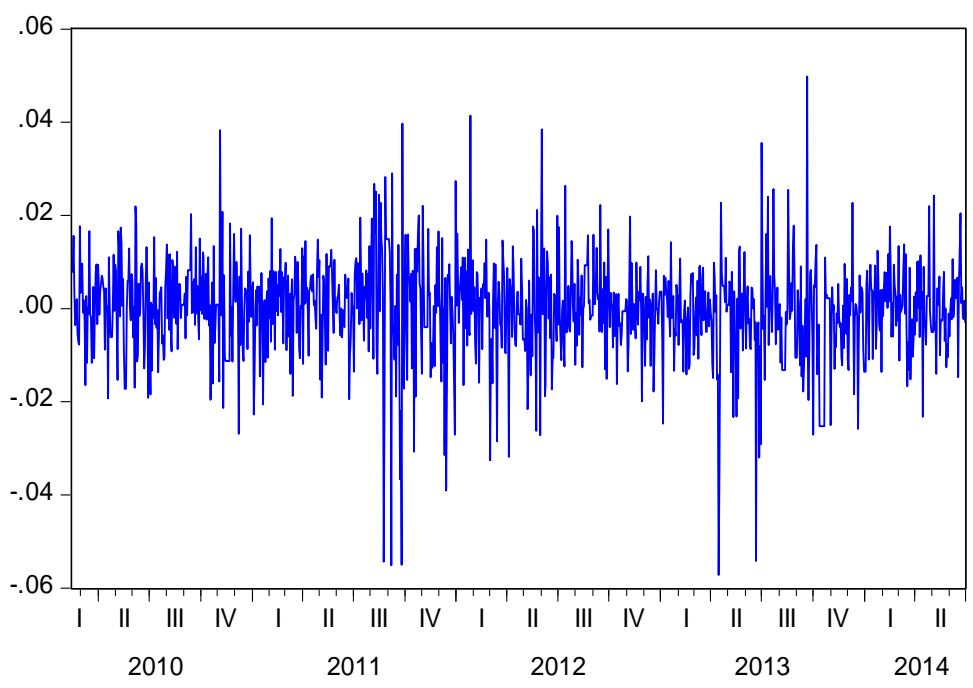

Figure 4. Gold return data

\section{Descriptive Statistics}

Before discussing the predictions of ARCH class models, a test has to be made in order to see if daily returns on financial markets have variable variance structure. Table 1 provides some descriptive statistics which are important for determination $\mathrm{f}$ the conditional variance model of return variable.

Table 1. Descriptive statistics

\begin{tabular}{cc}
\hline Size & 1142 \\
Mean & St.Dev. \\
0.000129 & 0.010839 \\
Max & Min \\
0.049795 & -0.057174 \\
Skewness & Kurtosis \\
-0.558452 & 6.641762 \\
JB & p value \\
690.4298 & $\mathrm{p}=0.00$ \\
ARCH $(2) \mathbf{L M}$ & $\mathbf{L M ~ p ~ v a l u e}$ \\
38.49221 & $\mathrm{p}=0.00$
\end{tabular}

\subsection{Methodology}

In this paper a multi-layered ANN model belonging to gold prices was constructed and back-propagation method was determined as learning algorithm first. Back-propagated networks have a structure where output and intermediate layer outputs back-propagate to input units. The exit of the neurons at output layer does not only depend on the current but also on previous input values. This characteristic is the reason for which back-propagation is preferred for usage in prediction models (Makay, 1992, p. 420). 


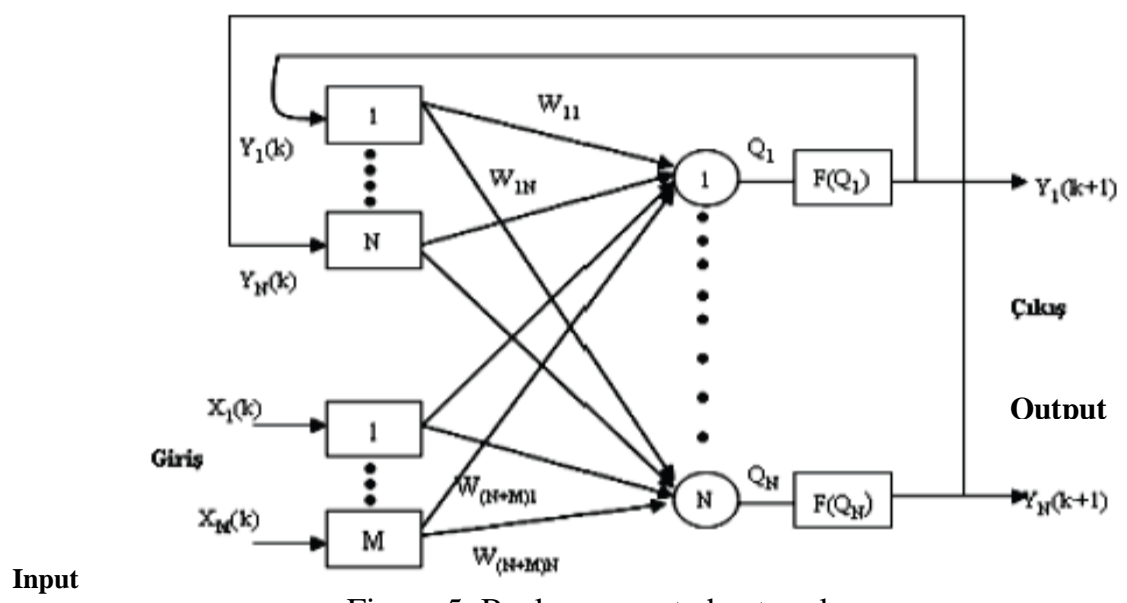

Figure 5. Back propagated networks

ANN models to construct also differ depending on the data to be used. Network architecture, the number of layers and neurons to be used, activation function, learning algorithm and parameters, and formation of education and test sets determine the success of the model. For this reason, previous studies in the literature were examined and the model which suits best to the study was constructed.

Daily gold prices were presented as the input data for modelling of artificial neural networks. However, the data were subjected to normalisation process before they were used in the network. Sigma function was employed as activation function at intermediate layers. Mean Absolute Error is the most widely used prediction accuracy criteria in measuring the performance of education test. Graph 1 provides the mean error squares reached at education stage.

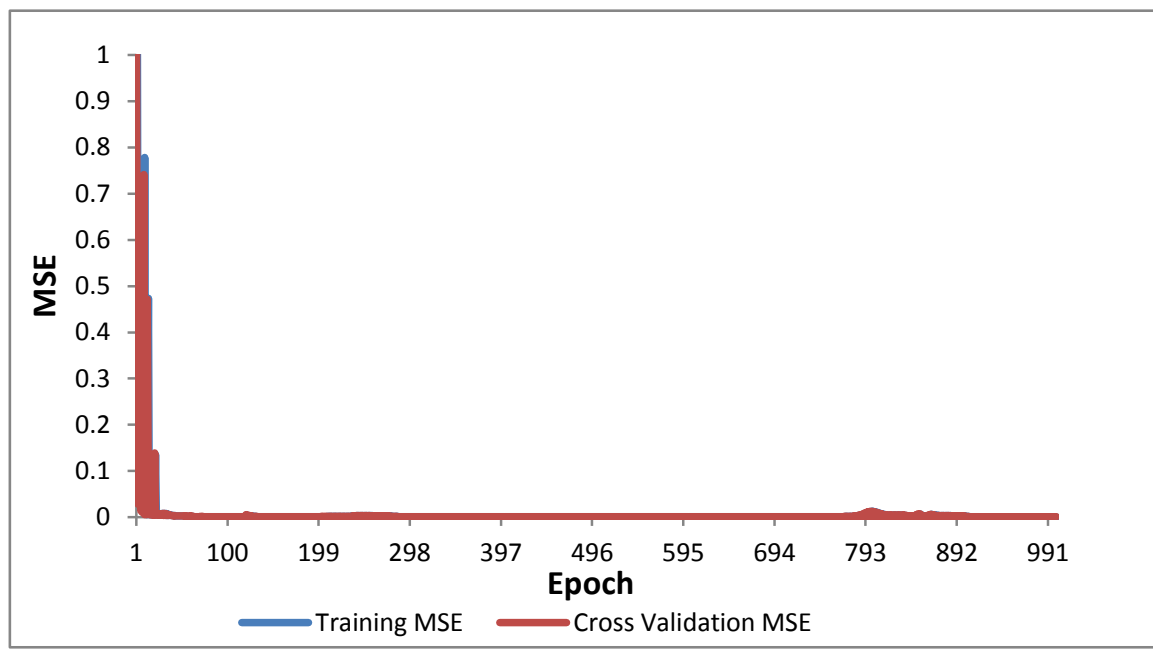

Figure 6. Education set performance

$1,2078.10^{-4}$ minimum MSE was obtained at 1000 updates of gold education testing performance, which shows that the artificial neural networks yielded very favourable results. The performance of the prediction is shown in figure 7 below. 


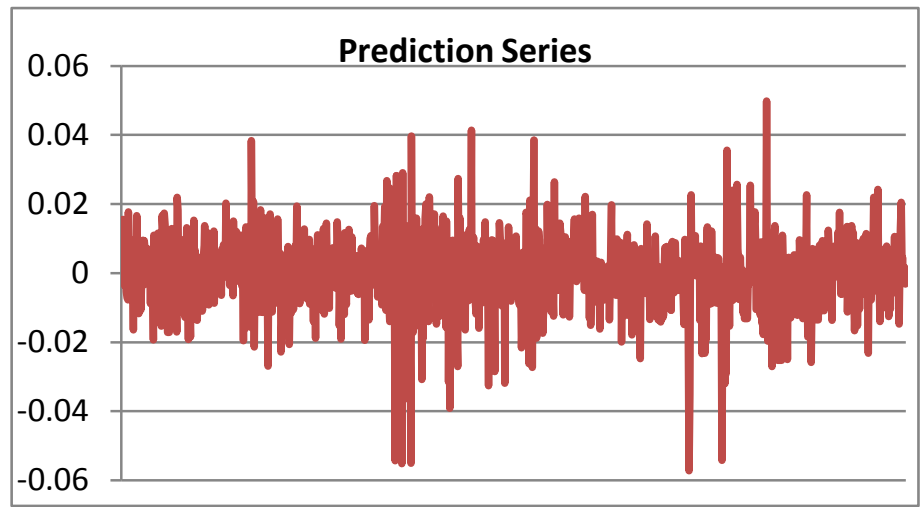

Figure 7. Gold return prediction values

When the prediction performance of gold price data are compared with the real data after the education performed at ANN, it can be seen that they have high performance both at learning stage and at prediction stage.

Non-linear ARCH models are used in the modelling of conditional variances which do not have normal distribution. When table 1 is examined, it can be seen that Gold Return series is not regularly distributed according to Jarque Bera (1980) (Bera, 1980, p. 255) test results. The existence of ARCH effect in return series was performed for 2 legs with ARCH LM test. ARCH effect is observed in the series.

\subsection{Determination of Proper ARIMA $(P, D, Q)$ Structure}

\subsubsection{Gold Return Series Unit Root Test}

In order to research whether the return series has unit root, time series and correlogram graphs were examined and it was observed that (i) the series oscillated around a certain mean value, (ii) auto-correlation coeffcients (ACF) did not assume very high values and (iii) they decreased rapidly as delay factor increased. These preliminary information display that return series is stable. ADF and PP unit root tests were applied in order to search integration level with test statistics. Akaike (AIC) and Schwartz (SC) criteria and Lagrange multiplier (LM) test statistics were used for decision-making. The results of this test are given in tables 2 and 3.

Table 2. ADF test unit root tests (level data)

\begin{tabular}{lccc}
\hline Unit root tests & With no constant term and trend & With constant term, without trend & With constant term and trend \\
\hline ADF statistics & $-31.51394 * * *$ & $-31.50432 * * *$ & $-31.67791^{* * *}$ \\
ADF "p" value & 0.0000 & 0.0000 & 0.0000 \\
\hline
\end{tabular}

$* * *, * *, * *$ define significance at $1 \%, 5 \%$ and $10 \%$ level respectively.

Table 3. PP test unit root tests (level data)

\begin{tabular}{lccc}
\hline Unit root tests & With no constant term and trend & With constant term, without trend & With constant term and trend \\
\hline PP statistics & $-31.5460^{* * *}$ & $-31.52464^{* * *}$ & $-31.67791^{* * *}$ \\
PP "p" value & 0.0000 & 0.0000 & 0.0000 \\
\hline
\end{tabular}

$* * *, * *, *$ define significance at $1 \%, 5 \%$ and $10 \%$ level respectively.

$\mathrm{ADF}$ and PP test results display that there are no unit roots at the Gold Return series. The return series is stable.

\subsubsection{Determination of Gold Return Series AR(P) and MA(Q) Levels}

Time series cannot only be defined correctly with an autoregressive (AR) or a moving average (MA) process. But they can be defined with the ARMA (p,q) model which was introduced by Wold (1938) to the literature which combines these two structures and is called aggregate autoregressive moving average. In this section the suitable ARMA (p,q) structure of the return series was studied within the scope of Box Jenkins approach. In in 
line with the stinginess principle, the models that reach ARMA $(4,4)$ level were predicted. The selection among models with statistically significant coefficients took into consideration the size of AIC and SC selection criteria, high determination coefficient $\left(\mathrm{R}^{2}\right)$, high logarithmic probability function (LL), and low Theil inequality coefficient. The results are given in table 4 .

Table 4. Determination of suitable $\operatorname{ARMA}(\mathrm{p}, \mathrm{q})$ structure

\begin{tabular}{rcc}
\hline & ARMA $(1,1)$ & ARMA $(1,3)$ \\
\hline AIC & -6.215298 & -6.179809 \\
SC & -6.202047 & -6.157725 \\
R $^{2}$ & 0.467764 & 0.450466 \\
LL & 3548.827 & 3530.581 \\
TIC & 0.984246 & 0.988582 \\
\hline
\end{tabular}

Statistically significant coefficients for gold return series were obtained from ARMA $(1,1)$ and ARMA(1,3) equations. Of these two definitions, ARMA $(1,1)$ model with smaller AIC and SC criteria value, higher $\mathrm{R}^{2}$ value and lower TIC value was preferred. ARMA $(1,1)$ model will be taken into consideration when modelling the conditional variance.

Engle (1982) ARCH LM test was conducted for 1,2,12 and 32 levels so that ARCH effect could be investigated in ARMA $(1,1)$ model. The results are given in table 5 .

Table 5. Testing ARMA $(1,1)$ ARCH Effect

\begin{tabular}{lcc}
\hline ARMA(1,1) & LM Statistic & LM Test “p” Value \\
\hline ARCH(1) & $27.13767^{* * * *}$ & 0.0000 \\
$\operatorname{ARCH}(2)$ & $36.95147^{* * *}$ & 0.0000 \\
$\operatorname{ARCH}(12)$ & $58.61884^{* * *}$ & 0.0000 \\
$\operatorname{ARCH}(32)$ & $81.33557^{* * *}$ & 0.0000 \\
\hline
\end{tabular}

$* * *, * *, *$ define significance at $1 \%, 5 \%$ and $10 \%$ level respectively.

When table 4 is examined, it can be seen that there is a strong ARCH effect for all levels at ARMA (1,1) residuals. The null hypothesis which claims that $\mathrm{ARCH}$ effect is non-existent is rejected.

\section{Determination of GARCH Model}

Predictions were made belonging to the GARCH, GJR GARCH and EGARCH models of which structures were detailed before. In order to be able to make the right choice among these models, the statistical significance of coefficients, validity of model restriction conditions, AIC and SIC selection criteria, $\mathrm{R}^{2}$ value, DW-d statistic, and LL value were taken into consideration. The cost-benefit analysis for choosing the right model is usually ignored. In these cases, some statistical prediction error measurement techniques are considered (Poon \&Granger, 2003, p. 478). Among symmetric prediction criteria, mean standard error (MSE), mean absolute error (MAE, mean percentage absolute error (MAPE) and Theil inequality coefficient (TIC) were used for selection. The low levels of these values ensure the selection of relevant model. The results are given in table 6 .

Table 6. Predictions of GARCH Models

\begin{tabular}{cccc}
\hline & GARCH (1,1) & EGARCH (1,1) & GJR GARCH (1,1) \\
\hline & & ARIMA EQUATION & $-2,01 \mathrm{E}-06^{*}$ \\
Constant & $-2.05 \mathrm{E}-06^{*}$ & $-1.94 \mathrm{E}-06^{*}$ & $0.085748^{*}$ \\
AR(1) & $0.055156^{*}$ & $0.084676^{* * *}$ & $-0.998405^{* * *}$ \\
MA(1) & $-0.998314^{* * *}$ & $-0.998369^{* * *}$ & \\
\hline
\end{tabular}




\begin{tabular}{cccc}
\hline & & VARIANCE EQUATION & \\
\hline$\alpha_{0}$ & $3.22 \mathrm{E}-06^{* * *}$ & $-5.540334 * * *$ & $0.030432^{* * *}$ \\
$\alpha_{1}$ & $0.042084^{* * *}$ & $0.130899^{* * * *}$ & $0.040618^{* * *}$ \\
$\gamma$ & & $-0.233883^{* * *}$ & $0.899323 * * *$ \\
$\beta$ & $0.929996^{* * *}$ & $0.403078^{* * *}$ & 1142 \\
Observation & 1142 & 1142 & $\mathbf{6 . 2 8 9 2 7 8}$ \\
AIC & -6.288179 & -6.271804 & -6.258381 \\
SC & $\mathbf{- 6 . 2 6 1 6 9 6}$ & -6.240907 & $\mathbf{0 . 4 6 7 4 2 1}$ \\
R2 & 0.467397 & 0.467159 & 1.99308 \\
DW - d & 1.987238 & 2.048764 & $\mathbf{3 5 9 8 . 1 7 7}$ \\
LL & 3596.550 & 3588.200 & $\mathbf{0 . 0 0 0 1 1 6 7 0 4}$ \\
MSE & 0.000116706 & 0.000116726 & $\mathbf{0 , 0 0 7 8 2 1}$ \\
MAE & 0.007838 & 0.007823 & $\mathbf{1 0 5 . 4 2 1 6}$ \\
MAPE & 105.4544 & 105.5056 & $\mathbf{0 . 9 3 2 1 7 6}$ \\
TIC & 0.983686 & 0.932818 & \\
\hline
\end{tabular}

$* * *, * *, *$ define significance at $1 \%, 5 \%$ and $10 \%$ level respectively.

When table 6 is examined, it can be seen that the most appropriate GARCH model is GJR GARCH $(1,1)$ model. The coefficients of this model are statistically significant and have the lowest AIC criteria value and the highest $\mathrm{R}^{2}$ and LL values. As the case in all models, autocorrelation does not exist. GJR GARCH model has lower values in prediction criteria.

Following the selection of the best GARCH model, ARCH LM test statistic was used on GJR GARCH residuals in order to test whether ARCH effect in the model continued. Autocorrelation test is based on Q test values. The results are given in table 7 .

Table 7. ARCH LM and Q statistical test for GJR GARCH model

\begin{tabular}{ccccc}
\hline GJR GARCH (1,1) & LM statistic & LM Test "p" value & Q test statistic & Q Test "p" value \\
\hline Lags (1) & 0.300618 & 0.5836 & 0.0008 & 0.977 \\
Lags (2) & 0.443860 & 0.8010 & 1.3644 & 0.506 \\
Lags (12) & 3.482825 & 0.9911 & 8.1216 & 0.776 \\
Lags (32) & 10.3800 & 0.9999 & 34.049 & 0.369 \\
\hline
\end{tabular}

An examination of table 7 reveals that ARCH effect on GJR GARCH $(1,1)$ residuals disappeared and that autocorrelation does not exist in residuals.

The measurement of the risk of gold as a financial instrument can be performed with volatility analysis. Volatility can be defined as momentary changes and movements in the prices of financial assets. In addition to the knowledge of future prices, it is essential that the investor can foresee the risk as well. In this sense modelling of the volatility feature and using it in prediction is highly important. The basic question in volatility literature is whether financial return volatility is predictable and, if it is, which model should be used to make the best prediction. In order to be able to answer this question this study was conducted to choose the best model which determines the volatility of gold prices in Turkey. The closing prices (USD/ounce) for 12.02.2010 30.06.2014 period were used for this purpose. Return series conversion was applied to the data.

A variety of GARCH models, which can be classified as conditional volatility models, were evaluated in order to obtain the best prediction. The study concluded that the most successful model in explaining the volatility of gold prices is GJR GARCH model. In this model the difference in the impact created by bad news and good news on gold return conditional variance can be observed. The model considers that positive and negative shocks 
are not symmetrical. It has been found out that the news impact on gold return in Turkey is asymmetrical. The coefficient which displays the leverage effect is not zero. The good news is unexpected rise in the series. In the case of a bad news, the model responses with 0.07096 parameter. The positive coefficient obtained in GJR GARCH model displays the existence of leverage effect, which shows that the negative news will be more effective than positive news on volatility.

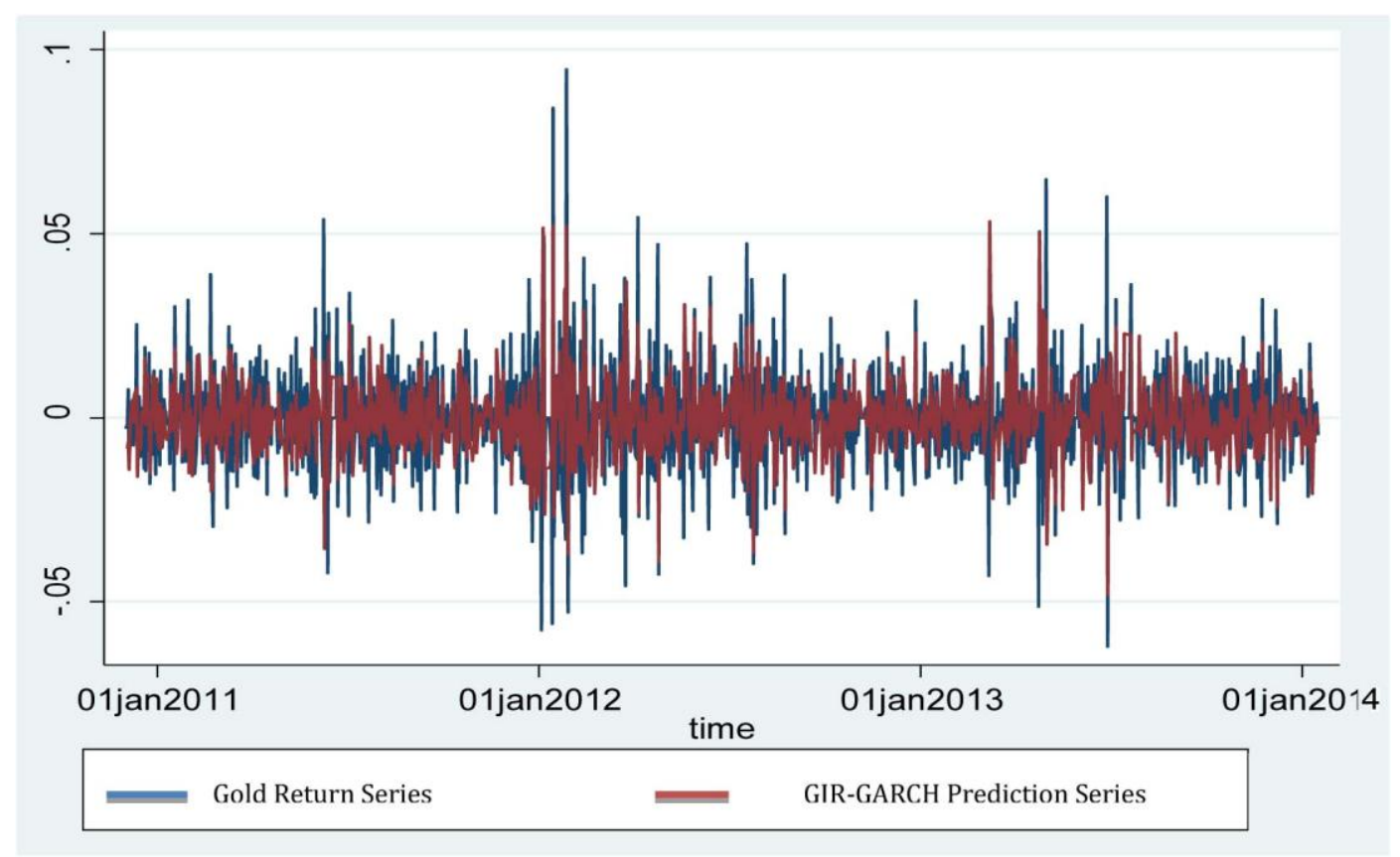

Figure 8. GJR GARCH $(1,1)$ results

Table 8. ANN and GJR GARCH $(1,1)$ Prediction performance values

\begin{tabular}{ccc}
\hline & ANN & GJR GARCH (1,1) \\
\hline MSE & 0.000120781 & 0.000116704 \\
MAE & 0.00796 & 0,007821 \\
\hline
\end{tabular}

Based on both prediction models, it can be evaluated that GJR GARCH model is a more effective prediction model for both MSE and MAE values.

\section{Conclusion}

For centuries, gold has been an indispensable instrument in financial system. Central banks demand gold as reserves, speculators demand it to determine their strategy, industries as input and individuals and investors for saving. The facts that it has been in the market for a very long time and that it has been accepted by economic units made gold and its return an essential issue.

Researchers have utilized a variety of prediction methods for predicting gold return. Conventional prediction methods take the lead. However, artificial neural networks have been put into use as an effective method recently.

In this paper, a conventional prediction model, GARCH and its derivatives and ANN were examined for gold return data of February 2010 and June 2014 period in Turkish Gold Stock Market. This study concluded that, contrary to the expectations and in disagreement with several studies in the literature. GJR GARCH model made a slightly more successful prediction compared to ANN. 


\section{References}

Aslanargun, A., Mammadagha, M., Yazıcı, B., \& Yolacan, Ş. (2007). Comparison of ARIMA, Neural Network and Hybrid Models in Time Series: Tourist Arrival Forecasting. Journal of Statistical Coumputation and Simulation, 77(1), 29-53. http://dx.doi.org/10.1080/10629360600564874

Bera, C. M. J. (1980). Efficient Tests for Normality, Homoscedasticity and Serial Independence of Regression Residuals. Economic Letter, 6, 255-259. http://dx.doi.org/10.1016/0165-1765(80)90024-5

Bildirici, M., \& Esin, Ö. (2012). Nonlinear Volatility Models in Economics: Augmented GARCH, APGARCH, FIGARCH AND FIAPGARCH Models. MPRA Working Paper, No: 40330. Retrieved from http://mpra.ub.uni-muenchen.de/40330/

Bollerslev, T. (1986). Generalized Autoregressive Conditional Heteroskedasticity. ARCH Selected Readings Advanced Texts in Econometrics, 44-48.

Bollerslev, T. (1987). A Conditionally Heteroskedastic Time Series Model for Speculative Prices and Rates of Return. The Review of Economics and Statistics, 69(3), 542-543. http://dx.doi.org/10.2307/1925546

Chen, W. Y., \& Lian, K. K. (2005). A Comparison of Forecasting Models For Asean Equity Markets. Sunway Academic Journal, 2(4).

Choudhary A., \& Haider, A. (2008). Neural Network Models for Influation Forecasting: An Apprasial. Discussion Papers in Economics, University of Surrey. Retrieved from http://www2.surrey.ac.uk/economics/files/dpaperspdf/2008_DP08-08.pdf_

Diaz-Robles, A. L., Ortega, J. C., Fu, S. J., Reed, D. G., Chow, C. J., Watson, G. J., \& Moncada-Herrera, J. A. (2008). A Hybrid ARIMA and Artifical Neural Networks Model to Forecasting Particulate Matter in Urban Areas: The Case of Temuco, Chile. Atmospheric Environment, 42, 8331-8340. http://dx.doi.org/10.1016/j.atmosenv.2008.07.020

Donaldson, G. R., \& Kamstra, M. (1997). An Artificial Neural Network - GARCH Model for International Stock Return Volatility. Journal of Empirical Finance, 4, 17-46. http://dx.doi.org/10.1016/S0927-5398(96)00011-4

Engle, R. F. (1982). Autoregressive Conditional Heteroskedasticity with Estimates of the Variance of U.K. Inflation. Econometrica, 50, 987-1008. http://dx.doi.org/10.2307/1912773

Fahimifard, S. M., Homayounifar, M., Sabouhi, M., \& Moghaddamnia, A. R. (2009). Comparison of ANFIS, ANN, GARCH and ARIMA Techniques to Exchange Rate Forecasting. Journal of Applied Science, 9(20), 3641-3651. http://dx.doi.org/10.3923/jas.2009.3641.3651

Glosten, L. R., Jagannathan, R., \& Runkle, D. E. (1993). On The Relation between The Expected Value and The Volatility of Nominal Excess Return on Stocks. Journal of Finance, 48, 1779-1801. http://dx.doi.org/10.1111/j.1540-6261.1993.tb05128.x

Gökçe, A. (1998). Zaman Serilerinde Koșullu Değişen Varyanslılık Yapısl: ARCH Modelleri - Döviz ve Sermaye Piyasalarına Bir Uygulama. Doktora Tezi, Gazi Üniversitesi Sosyal Bilimler Enstitüsü Ankara.

Greene, W. H. (1993). Econometric Analysis (2nd ed., p. 570). New York: Macmillan Publishing Co.

Griffiths, E. W., Hill, C. R., \& Judge, G. G. (1993). Learning and Praticing Econometrics (p. 640). John Wiley \& Sons Inc.

Hamzaçebi, C. (2008). Improving Artifical Neural Networks' Performance .n Seasional Time Series Forecasting. Journal Information Science, 178(23), 4550-4559. http://dx.doi.org/10.1016/j.ins.2008.07.024

Hui, L., Hong-qi, T., \& Yan-Fei, L. (2012). Comparison of Two New ARIMA-ANN and ARIMA-KALMAN Hybrid Methods for Wind Speed Prediction. Applied Energy, 98, 415-424. http://dx.doi.org/10.1016/j.apenergy.2012.04.001

Lineesh, M. C., Minue, K. K., \& John, C. J. (2010). Analysis of Nonstationary Nonlinear Economic Time Series of Gold Price: A Comparative Study. International Mathematical Forum, 5, 1673-1683.

Makay, D. J. C. (1992). Bayesian Interpolation. Nural Computation, 4, 415-447. http://dx.doi.org/10.1162/neco.1992.4.3.415

Mombeini, H., \& Yazdani-Chamzini, A. (2015). Modelling Gold Price via Artifical Neural Network. Journal of Economics, Business and Management, 3(7). http://dx.doi.org/10.7763/JOEBM.2015.V3.269 
Moshiri, S., \& Cameron, N. (2000). Neural Network Versus Econometric Models in Forecasting Inflation. Journal of Forecasting, 201-217. http://dx.doi.org/10.1002/(SICI)1099-131X(200004)19:3<201::AID-FOR753>3.0.CO;2-4

Nelson, D. B. (1991). Conditional Heteroskedasticity in Asset Returns: A New Approach. Econometrica, 59(2), 350. http://dx.doi.org/10.2307/2938260

Nitin, M., Saxena, P. V., \& Pardasani, K. R. (2010). A Comparison between Hybrid Approaches of ANN and ARIMA for Indian Stock Trend Forecasting. Business Intelligence Journal, 1, $23-41$.

Özdemir,O., Memedaga, M., \& Akhlitdin, N. (2010). ANN Models and Bayesian Spline Models for Analyzing of Exchange Rates and Gold Price. International Econometric Review, 5(2), 53-69.

Özden, Ü. H. (2008). İMKB Bileşik 100 Endeksi Getiri Volatilitesinin Analizi. İstanbul Ticaret Universitesi Sosyal Bilimler Dergisi, 13, 340-342.

Özkan, F. (2013). Comparing the Forecasting Performance of Neural Network and Purchasing Power Parity: The Case of Turkey. Economic Modelling, 31, 752-758. http://dx.doi.org/10.1016/j.econmod.2013.01.010

Parisi, A., Parisi, F., \& Diaz, D. (2008). Forecasting Gold Price Changes: Rolling and Recursive Neural Network Models. Journal of Multination Financial Management, 18, 477-487. http://dx.doi.org/10.1016/j.mulfin.2007.12.002

Poon, S., \& Granger, C. W. J. (2003). Forecasting Volatility in Financial Markets: A Review. Journal of Economic Literature, XLI, 478-539. http://dx.doi.org/10.1257/jel.41.2.478

Racelli, V., Bevilacqua, V., \& Azzolini, M. (2011). An Artifical Neural Network Model to Forecasting Exchange Rates. Journal of Intelligent Learning Systems and Applications, 3, 57-69. http://dx.doi.org/10.4236/jilsa.2011.32008

Roy, S., \& Singh, P. (2014). Stock Index Price Prediction of Gold Using Ensemble of ANN Architectures. Proceeding of 10th IRF International Conference (pp. 99-104), India.

Saiful, A., \& Mikami, Y. (2011). Comparing Accuary Performance of ANN, MLR and GARCH Model in Predicting Time Deposit Return of Islamic Bank. International Journal of Trade, Economics and Finance, $2(1), 44-51$.

Shafiee, S., \& Topal, E. (2010). An Overview of Global Gold market and Gold Price Forecasting. Journal of Forecasting, 17, 81-107.

Suganthi, L., \& Annand, A. S. (2012). Energy Models for Demand Forecasting. Renewable and Sustainable Energy Reviews, 16(2), 1223-1240. http://dx.doi.org/10.1016/j.rser.2011.08.014

Terasvirta, T. (2009). An Introduction to Univariate GARCH Models. Handbook of Financial Time Series, Springer, 34-35.

Termizel, T. T., \& Casey, M. C. (2005). A Comparative Study of ANN Hybrids. Neural Networks, 18(5-6), 781-789. http://dx.doi.org/10.1016/j.neunet.2005.06.003

Tosunoğlu, N., \& Benli, Y. (2012). Morgan Stanley Capital International Türkiye Endeksinin Yapay Sinir Ağları ile Öngörüsü. Ege Academic Review, 12(4), 541-547.

Tully, E., \& Lucey, M. B. (2005). Seasonality, Risk and Return in Daily COMEX Gold and Silver Data 1982-2002. IIIS Discussion Paper. from http://www.tcd.ie/iiis/documents/discussion/pdfs/iiisdp57.pdf

Tully, E., \& Lucey, M. B. (2007). A power GARCH Examination of the Gold Market. Research in International Business and Finance, 21, 316-325. http://dx.doi.org/10.1016/j.ribaf.2006.07.001

Wold, H. (1938). A Study in the Analysis of Stationary Time Series. Almgrist \& Wiksell, Stockholm.

Zhang, G. P. (2003). Time Series Forecasting Using a Hybrid ARIMA and Neural Network Model. Neurocomputing, 50, 159-175. http://dx.doi.org/10.1016/S0925-2312(01)00702-0

\section{Copyrights}

Copyright for this article is retained by the author(s), with first publication rights granted to the journal.

This is an open-access article distributed under the terms and conditions of the Creative Commons Attribution license (http://creativecommons.org/licenses/by/3.0/). 